\title{
A Fuzzy-Network Analysis Approach for Modeling and Analyzing Team Dependencies in Product Development Projects
}

\author{
Messa Alhammadi, Hamdi Bashir \\ Department of Industrial Engineering and Engineering Management, University of Sharjah, Sharjah, United Arab Emirates \\ Email address: \\ U18105008@sharjah.ac.ae (M. Alhammadi), hbashir@sharjah.ac.ae (H. Bashir) \\ To cite this article: \\ Messa Alhammadi, Hamdi Bashir. A Fuzzy-Network Analysis Approach for Modeling and Analyzing Team Dependencies in Product \\ Development Projects. Engineering and Applied Sciences. Vol. 6, No. 1, 2021, pp. 18-25. doi: 10.11648/j.eas.20210601.12
}

Received: February 6, 2021; Accepted: March 11, 2021; Published: March 17, 2021

\begin{abstract}
Developing a complex product in a concurrent engineering environment requires managing information flow among ten or even hundreds of people of different specialties organized in a large number of product development (PD) teams. Managing these teams effectively requires understanding the level of information dependencies among them which are often vague and cannot be precisely predicted. Taking into account the limitations of relevant previous studies, this article proposes a fuzzy-social network analysis approach for modeling and analyzing the information flow among PD teams. The approach involves four major steps: mapping of dependencies, measuring the level of information dependencies based on the fuzzy set theory, visualizing the network, and performing quantitative analysis using three measures (network density, in-degree centrality, and out-degree centrality). To validate its practicality, the approach is used to model and analyze the dependencies among $22 \mathrm{PD}$ teams in a real project adapted from the literature and involved developing an automobile engine. An advantage of the approach is that in addition to providing a holistic view of the interactions among PD teams, it permits PD project managers to identity the most important PD teams with respect to information flow control using a proposed new classification system that classifies PD teams under four categories: autonomous, receivers, transmitters, and transceivers.
\end{abstract}

Keywords: Concurrent Engineering, Product Development Teams, Information Flow, Fuzzy, Social Network Analysis

\section{Introduction}

Developing innovative products rapidly at a minimum cost is essential to maintain high competitiveness in increasingly global markets [1-3]. To overcome the limitation of a lengthy and traditional serial product development process, many companies opted to adopt the engineering and management philosophy of concurrent engineering that emerged in the 1980 s for product development $[4,5]$. In addition to reducing product development time, and thus time to the market, the reported benefits of this practice include reduced costs, fewer engineering changes, a lessening of defects, a reduction of rework and scrap, higher quality and return on assets [6]. In concurrent engineering, the product development process can be accelerated through performing parallel and interdependent (coupled) activities in addition to dependent activities by cross-functional product development (PD) teams. These teams need to continuously exchange information on specified activities to integrate the product's final structure [7]. Thus, communication between and among PD teams can be described by an information structure created by unidirectional and bidirectional information transmission among PD teams. This structure can be complex due to performing a large number of coupled activities, which are essential for achieving high efficiency and optimal performance in concurrent product development [8]. The structure can be even more complex in projects that involve developing complex products-such as automobiles, airplanes, and others - that require the involvement of hundreds or even thousands of specialists. For instance, the number of people involved in developing an automobile can reach more than 1600 , whereas the number of those working on the development of an airplane can reach more than 16,000 [9]. Therefore, creating effective information flow among PD teams is a critical success factor in PD [10-14]. The concern of this current paper is on modeling and 
analyzing information flow among PD teams, which is an important aspect for creating effective communication and coordination strategies, thus creating an improved PD process [14]. A brief review of the studies that have addressed this issue is given below.

\section{Literature Review}

McCord and Eppinger [15], perhaps, one of the earliest studies tackling the issue of how to capture and analyze information flow among PD teams. In that study, design structure matrix (DSM) was utilized to capture the frequency and direction of information flow among teams in an automobile engine development project. Browning [16] investigated mechanisms among cross-functional development teams and then applied them to developing a Boeing F/A-18E/F program. This study was then complemented by the work of Eppinger [17], in which clustering was used to reorganize the teams to improve instream integration. Loch and Terwiesch [8] developed a model for information dependency among teams who perform overlapping activities. Additionally, they created an overlapping model for managing interdependent tasks. To facilitate organizing teams in concurrent engineering projects, Leenders and Dolfsma [18] put forward a method for grouping interdependent design. The method involves using DSM to represent binary relationships among tasks after which the relationships are quantified using analytic hierarchy process. In Batallas and Yassine [7], DSM usage is complemented with social network analysis (SNA) to identify vital team players in PD networks as well as to form an information leader's team - a central team that can deal with large amounts of information, which can often cause a bottleneck. Kratzer et al. [19] investigated relationships among product development teams and their creativity. The relationships among teams were measured using a rating scale " $(0=$ no interaction; $1=$ (at least $)$ monthly interaction, $2=$ (at least) weekly interaction; and $3=$ (at least) daily interaction)". These relationships were then modeled by a social network. Chu et al. [14] proposed to use a DSM based approach for measuring interaction strength among PD teams, and then to use a two-stage clustering criterion model for clustering organizational units in order to reduce coordination time.

Clearly, above brief review demonstrates that few studies have dealt with issue of modeling and analyzing information flow among PD teams. The most common tools in these studies are DSM and SNA. DSM was originally developed by Steward [20] for representing the interactions among components of system, product, or process. Since then, DSM has become one of the most widely used modeling frameworks across several areas of research, including engineering management, engineering design, systems engineering, and management/organization science [21]. A traditional DSM is an $n \times n$ square matrix, where $n$ is the number of elements to be modeled (e.g., development teams). In this matrix, the elements are listed at the top and along the left-hand side. If element $i$ depends on element $j$ (e.g., team $i$ needs information from team $j$ ), then a mark " $\bullet$ " or " $\times$ " is inserted in cell $\mathrm{e}_{i j}$. Otherwise, cell $\mathrm{e}_{i j}$ is left blank. Alternatively, "ones" and "zeros" are used instead of marks and empty cells. In some DSM applications, the weighted relationships among elements are considered. One limitation of DSM is that it does not reveal accumulated or multilevel dependencies [22]. The other limitation of DSM and its variants is the lack of measures that can be used for measuring properties of information flow to analyze the location of individual PD teams within the information network, and thus identify the important PD teams that might need special attention for improving the PD process. To overcome this limitation, Batallas and Yassine [7] used SNA and seven associated measures, namely, degree centrality, closeness centrality, betweenness centrality, and four brokerage measures (gatekeeper, liaison, internal coordinator, and external coordinator). The top 10 scoring PD teams in these measures are considered as the most significant in terms of information flow control. Moreover, Batallas and Yassine [7] proposed two procedures for selecting the most important teams in case of the appearance of some teams in the top 10 positions in more than one measure.

\section{Research Objectives}

Regardless of the used tools (whether DSM or SNA), a common limitation of most previous studies is the use of binary relations ( 0 or 1 ) or weightings assuming that they can be easily predicted to represent the relationships among PD teams. In practice, the relationships cannot be binary and the level of information dependencies among PD teams are often vague and cannot be precisely predicted. Taking into account the limitations of relevant previous studies, this current paper proposes using a fuzzy-SNA approach for modeling and analyzing information dependencies among PD teams. By modeling and analyzing information dependencies using the proposed approach, the most important PD teams with respect to information flow control can be easily identified. The remaining part of the paper is organized as follows. A brief introduction to SNA is given in Section 4, and Section 5 describes the proposed approach. Lastly, Section 6 contains the conclusion of this research.

\section{Social Network Analysis (SNA)}

SNA emerged in the 1930s in the field of sociology to study the relationships between social entities, referred to as actors [23]. However, during the past three decades, SNA has been progressively applied to various other fields, including project and engineering management, where its applications were extended to modeling interactions among non-human objects [5, 18, 24-26]. Most of the early SNA applications considered either binary or weighted relationships among actors. However, there has been recent interest in using a fuzzy approach to SNA to deal with vague and imprecise relationships among actors in some applications [27-32]. 
A main advantage in the use of SNA is visualizing the interactions among the actors by a network consisting of nodes and arcs. The arcs can be either directed or undirected. Moreover, SNA helps in analyzing the structure of a network using several measures. Among the most applicable measures for analyzing information dependencies among PD teams are network density (a network-level measure) in conjunction with degree-centrality measures (node-level measures). In the context of this current study, network density can be used as an indication of the level of the complexity of managing a project due to the complex dependencies among PD teams. The implication is that, if the network density is found to be high, then an action need be implemented to reduce the network density, for instance, by combining highly interdependent PD teams into one team. Degree-centrality measures are useful for the identification of the importance and/or classification of actors based on their relationships with others in the network.

\section{The Proposed Approach}

The proposed approach for analyzing dependencies among PD teams involves four major steps: (1) mapping of dependencies (2) measuring the level of information dependencies, (3) visualizing the network, (4) and performing quantitative analysis. These steps are explained through a demonstrative example adapted from McCord and Eppinger [15], which involves redesigning a small block V-8 automotive engine at General Motors by the following 22 teams, where a team is defined as a group of people with different specialties who work together and hold regular meetings
1. Engine Block
2. Cylinder Heads
3. Camshaft/Valve Train
4. Pistons
5. Connecting Rods
6. Crankshaft
7. Flywheel
8. Accessory Drive

\author{
16. Fuel System \\ 17. Throttle Body \\ 18.EVAP \\ 19. Ignition \\ 20. Engine control module \\ 21. Electrical System \\ 22. Engine Assembly
}

\subsection{Mapping of Information Dependencies}

In this step, a team of experts comprising a senior designer from each team is formed. The first task of this team is to prepare a matrix called "Structural Self-Interaction Matrix" (SSIM), adapted from the interpretive structural modeling [33]. In this matrix, four symbols are used to denote the direction of information flow between PD teams $i$ and $j$, as follows:
(1) $\mathrm{V}$ means that PD team $i$ transmits information to PD team $j$ (a forward relationship)

(2) A means that PD team $j$ transmits information to PD team $i$ (a backward relationship)

(3) X means that PD team $i$ and PD team $j$ exchange information (a mutual relationship)

(4) O means that PD team i and PD team j do not exchange information (no relationship)

Table 1. Structural Self-Interaction Matrix.

\begin{tabular}{|c|c|c|c|c|c|c|c|c|c|c|c|c|c|c|c|c|c|c|c|c|c|}
\hline PD Teams & 22 & 21 & 20 & 19 & 18 & 17 & 16 & 15 & 14 & 13 & 12 & 11 & 10 & 9 & 8 & 7 & 6 & 5 & 4 & 3 & 2 \\
\hline 1 & $X$ & $\mathrm{X}$ & $\mathrm{V}$ & $X$ & $\mathrm{O}$ & $\mathrm{O}$ & $\mathrm{O}$ & A & $\mathrm{O}$ & $X$ & $X$ & $X$ & $X$ & $\mathrm{X}$ & $\mathrm{X}$ & $\mathrm{X}$ & $\mathrm{X}$ & $X$ & $X$ & $\mathrm{X}$ & $\mathrm{X}$ \\
\hline 2 & $\mathrm{X}$ & $X$ & $\mathrm{~V}$ & $X$ & $\mathrm{O}$ & $\mathrm{A}$ & A & V & $\mathrm{O}$ & $X$ & $X$ & $X$ & $X$ & $X$ & $X$ & V & $X$ & V & $X$ & $X$ & \\
\hline 3 & $\mathrm{X}$ & $\mathrm{X}$ & $\mathrm{V}$ & $X$ & $\mathrm{O}$ & $\mathrm{O}$ & $\mathrm{O}$ & $\mathrm{O}$ & $\mathrm{O}$ & $\mathrm{O}$ & $\mathrm{O}$ & $X$ & $\mathrm{X}$ & $\mathrm{X}$ & V & $\mathrm{O}$ & $X$ & $\mathrm{O}$ & $X$ & & \\
\hline 4 & $\mathrm{X}$ & V & $\mathrm{O}$ & $X$ & $\mathrm{O}$ & $\mathrm{O}$ & A & $\mathrm{O}$ & $\mathrm{O}$ & $\mathrm{O}$ & $\mathrm{O}$ & A & $\mathrm{X}$ & $X$ & $\mathrm{O}$ & A & $X$ & $X$ & & & \\
\hline 5 & $X$ & $\mathrm{O}$ & $\mathrm{O}$ & $\mathrm{O}$ & $\mathrm{O}$ & $\mathrm{O}$ & $\mathrm{O}$ & $\mathrm{O}$ & $\mathrm{O}$ & $\mathrm{O}$ & $\mathrm{O}$ & $\mathrm{O}$ & A & X & $\mathrm{O}$ & $\mathrm{O}$ & X & & & & \\
\hline 6 & X & $\mathrm{V}$ & $\mathrm{X}$ & $\mathrm{X}$ & $\mathrm{O}$ & $\mathrm{O}$ & $\mathrm{O}$ & $\mathrm{O}$ & $\mathrm{O}$ & $\mathrm{O}$ & $\mathrm{O}$ & $\mathrm{O}$ & A & X & X & X & & & & & \\
\hline 8 & $\mathrm{X}$ & $\mathrm{X}$ & $\mathrm{X}$ & $\mathrm{X}$ & $\mathrm{A}$ & $\mathrm{X}$ & $X$ & $\mathrm{X}$ & $\mathrm{X}$ & $\mathrm{X}$ & $\mathrm{X}$ & $\mathrm{X}$ & $\mathrm{X}$ & $\mathrm{X}$ & & & & & & & \\
\hline 9 & $X$ & $\mathrm{X}$ & $\mathrm{V}$ & $\mathrm{X}$ & $\mathrm{O}$ & $\mathrm{O}$ & $\mathrm{O}$ & $\mathrm{O}$ & $\mathrm{O}$ & $\mathrm{O}$ & $\mathrm{X}$ & V & $\mathrm{X}$ & & & & & & & & \\
\hline 10 & $\mathrm{X}$ & $X$ & V & V & $\mathrm{O}$ & $\mathrm{X}$ & $X$ & V & A & $X$ & V & $X$ & & & & & & & & & \\
\hline 11 & $\mathrm{X}$ & $\mathrm{V}$ & $\mathrm{X}$ & X & $\mathrm{X}$ & $\mathrm{X}$ & $X$ & $X$ & X & $X$ & $X$ & & & & & & & & & & \\
\hline 12 & $X$ & $X$ & $X$ & $X$ & $\mathrm{O}$ & $\mathrm{O}$ & A & $X$ & X & $X$ & & & & & & & & & & & \\
\hline 13 & $\mathrm{X}$ & $X$ & $\mathrm{X}$ & $X$ & $\mathrm{O}$ & $\mathrm{X}$ & $X$ & $X$ & $\mathrm{O}$ & & & & & & & & & & & & \\
\hline 14 & $\mathrm{O}$ & $\mathrm{O}$ & $\mathrm{O}$ & $\mathrm{O}$ & $\mathrm{O}$ & $\mathrm{X}$ & $X$ & $X$ & & & & & & & & & & & & & \\
\hline 16 & $\mathrm{X}$ & $\mathrm{X}$ & $\mathrm{V}$ & V & $\mathrm{X}$ & $\mathrm{X}$ & & & & & & & & & & & & & & & \\
\hline 17 & $\mathrm{X}$ & $\mathrm{O}$ & $\mathrm{X}$ & $X$ & $X$ & & & & & & & & & & & & & & & & \\
\hline 18 & $\mathrm{~V}$ & X & $X$ & $\mathrm{O}$ & & & & & & & & & & & & & & & & & \\
\hline 19 & $X$ & X & $X$ & & & & & & & & & & & & & & & & & & \\
\hline 20 & $\mathrm{X}$ & X & & & & & & & & & & & & & & & & & & & \\
\hline 21 & X & & & & & & & & & & & & & & & & & & & & \\
\hline
\end{tabular}


For the demonstrative example, the relationships among the PD teams are extracted from the original data. Accordingly, the SSIM given in Table 1 is constructed. The SSIM is then converted to an $n \times n$ adjacency matrix, where $n$ represents the number of $\mathrm{PD}$ teams "by substituting the four symbols $(\mathrm{V}, \mathrm{A}, \mathrm{X}$, or $\mathrm{O})$ with $1 \mathrm{~s}$ and $0 \mathrm{~s}$. The rules for the substitution are as follows:

(1) "If the $(i, j)$ entry in the SSIM is V, then the $(i, j)$ entry in the adjacency matrix becomes 1 and the $(i, j)$ entry becomes 0 .

(2) If the $(i, j)$ entry in the SSIM is A, then the $(i, j)$ entry in the adjacency matrix becomes 0 and the $(i, j)$ entry becomes 1 .

(3) If the $(i, j)$ entry in the SSIM is X, then the $(i, j)$ entry in the adjacency matrix becomes 1 and the $(i, j)$ entry becomes 1 .

(4) If the $(i, j)$ entry in the SSIM is O, then the $(i, j)$ entry in the adjacency matrix becomes 0 and the $(i, j)$ entry becomes 0" [34].

Making the above substitution for the demonstrative example produces the adjacency matrix shown in Table 2.

Table 2. Adjacency matrix.

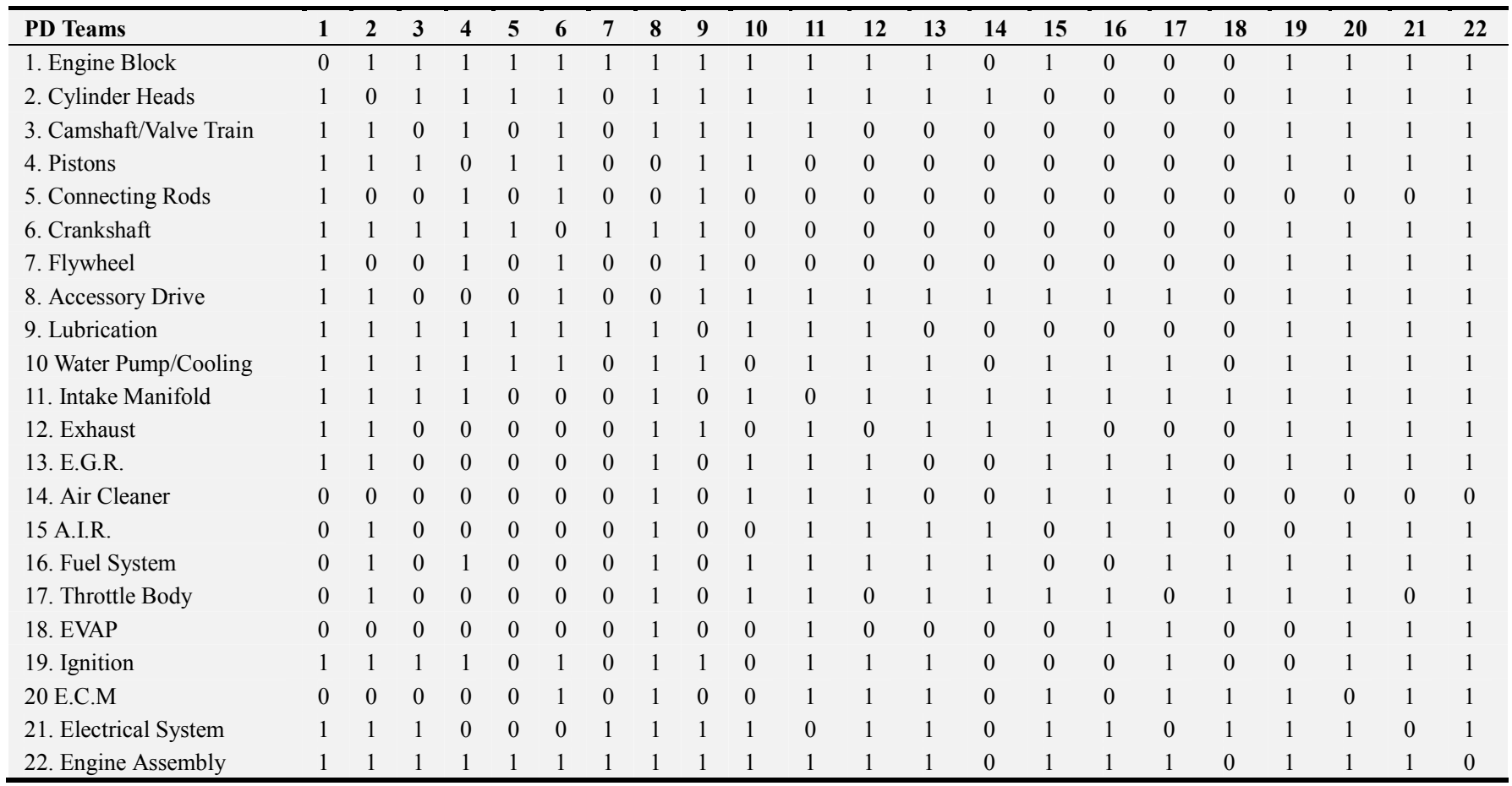

\subsection{Measuring the Level of Information Dependencies}

In this step, the binary values in the initial adjacency matrix are replaced with weights representing the level of information dependencies among PD teams using a fuzzy membership function [35]. These functions can be of different shapes, but triangular membership functions are used most frequently [36]. A triangular function is defined by a lower limit $a$, an upper limit $c$, and a value $m$, where $a<b$ $<c$ The points $a, b$, and $c$ represent the $x$ coordinates of the three vertices of membership function" $\mu_{\tilde{\mathrm{A}}}(x)$ "'in a fuzzy set $A$, defined by equation (1).

$$
\mu_{\tilde{\mathrm{A}}}(x)=\left|\begin{array}{c}
0 x<a \\
\frac{x-a}{m-a} a \leq x \leq b \\
\frac{c-x}{c-b} b \leq x \leq c \\
0 x>c
\end{array}\right|
$$

Assigning weight values to the relationships among PD teams are obtained as follows. Using the linguistic variables given in Table 3, each member of the team of experts is asked a number of his/her team to provide their subjective opinion on the level of information dependencies on the other PD teams identified in the adjacency matrix. For instance, according to the adjacency matrix, PD team 18 (Column 3) has information dependencies on PD teams 11, 16, 17, 20, and 21 (Rows 11, 16, 17, 20, and 21). Therefore, the member representing PD team 18 in the team of experts can ask a number of his/her PD team to use the linguistic variables given in Table 3 to provide their opinions on the levels of information dependencies of their team on each of PD teams $11,16,17,20$, and 21 . The assigned linguistic variables by the members are then changes into their corresponding fuzzy numbers shown in Table 3 . If the consensus approach is not adopted, then the simple average can be used for aggregation.

Table 3. Fuzzy linguistic scale.

\begin{tabular}{ll}
\hline Linguistic variable & Triangular fuzzy number \\
\hline No dependency & $(0.0,0.0,0.0)$ \\
Very low dependency & $(0.0,0.1,0.3)$ \\
Low dependency & $(0.1,0.3,0.5)$ \\
\hline
\end{tabular}




\begin{tabular}{ll}
\hline Linguistic variable & Triangular fuzzy number \\
\hline Medium dependency & $(0.3,0.5,0.7)$ \\
High dependency & $(0.5,0.7,0.9)$ \\
Very high dependency & $(0.7,0.9,1.0)$ \\
Complete dependency & $(1.0,1.0,1.0)$ \\
\hline
\end{tabular}

Once a fuzzy number is obtained for each level of dependency, either by consensus or averaging, Equation (2) is then used for the defuzzification of the fuzzy numbers into the best non-fuzzy performance (BNP) value in order to obtain a fuzzy adjacency matrix.

$$
B N P_{i j}=\frac{[(c-a)+(b-a)]}{3}+a
$$

-where $i j$ indicates the crisp possible rating of the dependency between PD teams $i$ and $j$.
Unfortunately, the above described procedure for assigning linguistic variables to the relationships among PD teams is not implemented in this study since the demonstrative example is adapted from the literature. In the original data of the example, the level of information dependencies among PD teams are represented by 5,3 , or 1 . Whereas 5 means high frequency of information exchange, 3 means medium frequency of information exchange, and 1 means low frequency of information exchange. Accordingly, this paper defined high frequency of information exchange as fuzzy triangular number $(0.5,0.7,0.9)$, medium frequency of information exchange as fuzzy triangular number $(0.3,0.5$, 0.7 ), and low frequency of information exchange as fuzzy triangular number $(0.1,0.3,0.5)$. Then by applying equation (2), the fuzzy adjacency matrix given in Table 4 obtained.

Table 4. Fuzzy adjacency matrix.

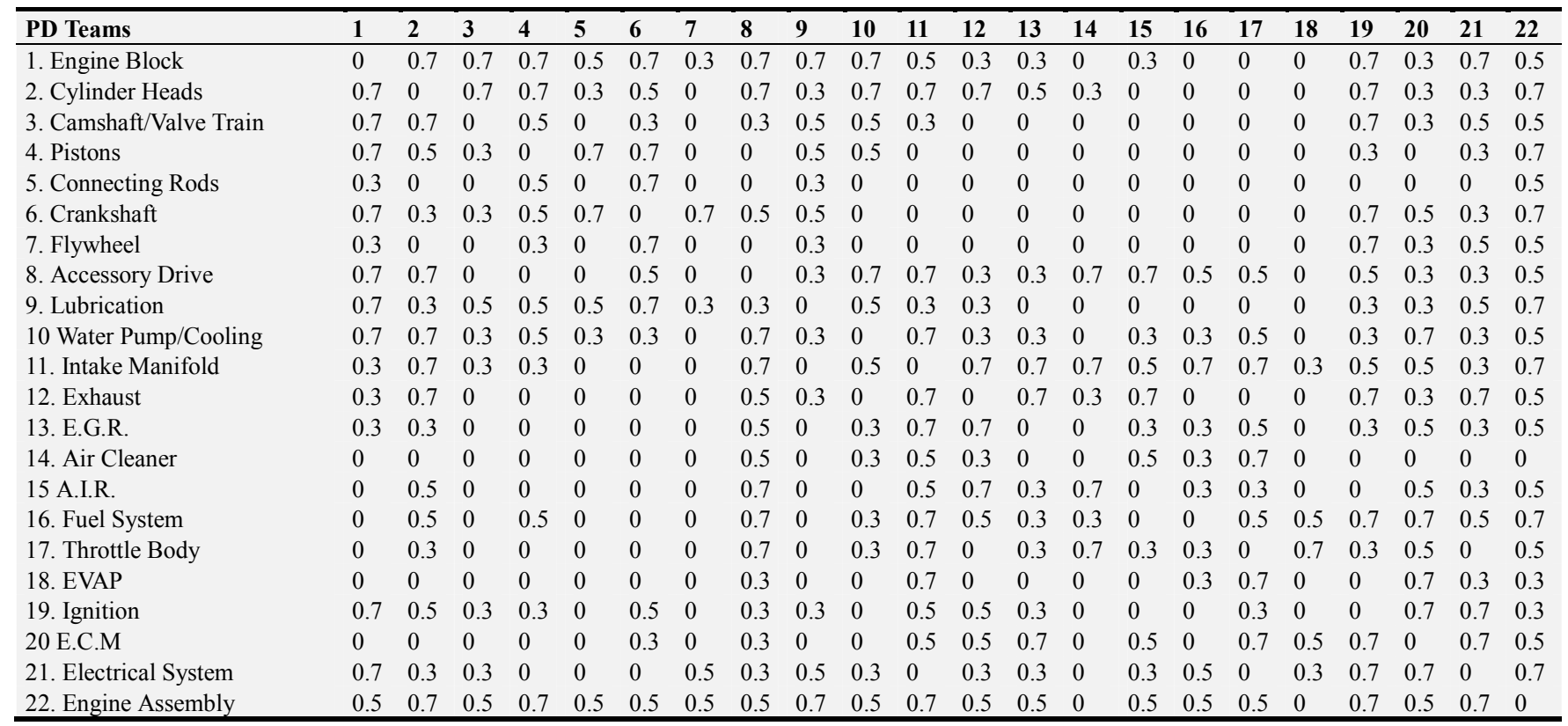

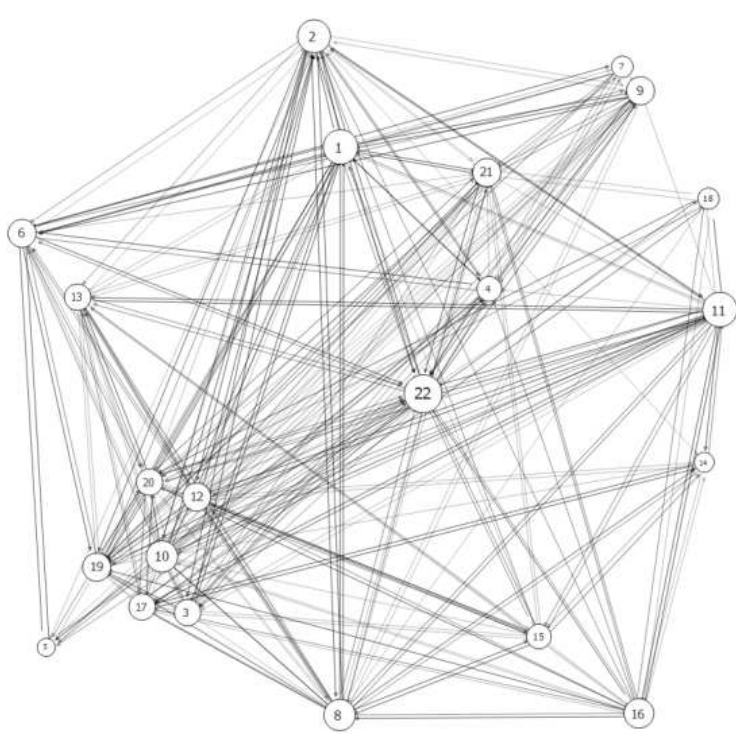

Figure 1. Team interaction network.

\subsection{Network Visualization}

In order to comprehend the interactions among the PD teams in the project, it would be useful to convert the fuzzy adjacency matrix to a network consisting of nodes and arcswhere the nodes represent the teams, and the arcs represent the existence of information flow among them. A visualized network can be useful for tasks such as exploring and comparing trends of information flow among PD teams. The network can be easily constructed using any of the SNA software packages with inputting an adjacency matrix. For the demonstrative example, the Social Network Visualizer (SocNetV) software package is used for constructing the network displayed in Figure 1 as well as for performing all the computations presented here. In this network, the nodes are sized to represent their corresponding out-degree values.

\subsection{Quantitative Analysis and Results}

In this step, the interdependencies among PD teams in 
terms of information flow are analyzed using density, indegree centrality, and out-degree centrality measures.

As indicated earlier, network density is useful for assessing the complexity of the information network structure. The density of a network can be computed by adding all the entries of the fuzzy adjacency and dividing by the maximum possible number of ties (edges). For the demonstrative example, the computed information network structure density is 0.3 . The in-degree centrality of PD team $j$ can be computed by adding all the entries in column $j$ of the fuzzy adjacency matrix, whereas the outdegree centrality of PD team $i$ can be computed by adding all the entries row $i$ of the fuzzy adjacency matrix. The computed outdegree centrality and in-degree centrality values for the demonstrative example are given in Table 5. Based on these values, PD teams can be classified in in terms of their information dependencies by constructing a diagram consisting of four quadrants similar to the driving power-dependence diagram utilized in cross-impact matrix multiplication applied to classification [37]. For the demonstrative example, the constructed diagram is shown in Figure 2. As shown in this figure, the first quadrant contains PD teams 4, 5, 6, 7, 9, 12, 13, 14,15 , and 17 . These PD teams have relatively low out-degree centrality and relatively low in-degree centrality; therefore, they can be called autonomous PD teams. The second quadrant contains teams with relatively low out-degree centrality but relatively high in-degree centrality; therefore, they can be called receivers. These PD teams are 19, 20, and 21 . The third quadrant contains teams $1,2,8,11$, and 22 which have relatively high out-degree and in-degree centrality; therefore, they can be called transceivers. The fourth quadrant contains teams 10 and 16: these have relatively high out-degree centrality but low indegree centrality; therefore, they can be transmitters.

Autonomous teams have the least amount of information exchange with other teams, i.e., they are insignificant in terms of information flow control. On the other hand, transmitters and transceivers are the most critical with respect to information flow control. Compared to other teams, transmitters have low level of information dependencies on others, but they are highly depended upon by others. Compared to other teams, transceivers have high level of information dependencies on others and also they are highly depended upon by others. In Batallas and Yassine [7], transceivers are also called information leaders. According to Batallas and Yassine [7], these teams have challenges, also they have opportunities. Since they exchange information with a large number of teams (they acquire and the same time send information), then in addition to performing their assigned tasks, they need also to devote a significant portion of time to communicating with other PD teams. Thus, their time need to be carefully managed in order to avoid to information bottlenecks but not on the expense of completing their assigned design work. Form the opportunities side, compared to others, these teams have the potential to participate in product's innovation [38] as a result of obtaining new knowledge through their interactions with many other teams.

Table 5. In-degree and out-degree centrality values.

\begin{tabular}{|c|c|c|c|c|c|}
\hline PD teams & In-degree centrality & Out-Degree centrality & PD Team & In-degree centrality & Out-Degree centrality \\
\hline 1 & 8.3 & 9.3 & 12 & 6.6 & 6.4 \\
\hline 2 & 8.4 & 8.8 & 13 & 5.5 & 5.5 \\
\hline 3 & 4.2 & 5.8 & 14 & 3.7 & 3.1 \\
\hline 4 & 6 & 5.2 & 15 & 4.9 & 5.3 \\
\hline 5 & 3.5 & 2.3 & 16 & 4 & 7.4 \\
\hline 6 & 6.4 & 6.4 & 17 & 5.9 & 5.6 \\
\hline 7 & 2.3 & 3.6 & 18 & 2.3 & 3.3 \\
\hline 9 & 5.5 & 6.7 & 20 & 8.6 & 5.9 \\
\hline 10 & 6.1 & 8 & 21 & 8.2 & 6.7 \\
\hline 11 & 9.4 & 9.1 & 22 & 11 & 10.7 \\
\hline
\end{tabular}

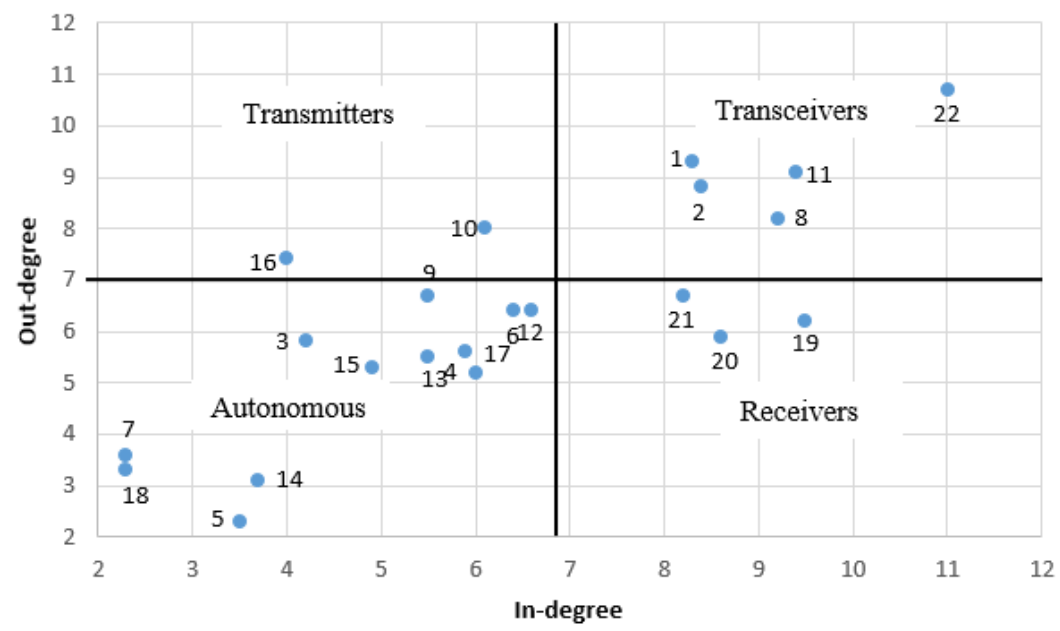

Figure 2. Out-in-degree centrality diagram. 


\section{Conclusions}

Modeling and analyzing information flow among PD teams is a challenging issue for product development projects. DSM and SNA were found to be most commonly used tools in the literature. This study proposed to overcome some of the highlighted limitation of these tools by using a fuzzy SNA. In addition to quantifying level of information dependencies among PD teams, the proposed approach involves the usage of three measures, namely, density, indegree and out-degree centrality. The last two measures are used for classifying the PD teams into four categories: autonomous, receivers, transmitters, and transceivers. PD teams belonging to the last category are the most important teams since the level of information either received form others or transmitted to others are high. In Batallas and Yassine [7], these PD teams are called information leaders. Thus, one advantage of our approach is to identify those PD teams by using only two measures. Another advantage of the suggested approach is the utilization of fuzzy set theory to deal with imprecise and vague information dependencies among PD teams. The value of the proposed approach was shown via an illustrative example adapted from the literature and involved a PD project comprising 22 teams for developing an automobile engine.

However, the proposed approach has several limitations that might be overcome in future studies. First, this study assumes that the level of information dependencies among PD teams remains fixed throughout project execution. Second, although fuzzy sets may be a suitable approach for quantifying the level of information dependencies; some other approaches may be explored. Lastly, besides the measures utilized in this study and in previous studies, other measures likely exist that might be useful for analyzing information flow from different perspectives.

\section{References}

[1] Cheng, X., Lan, X. G., and Zhu, Q. (2015) 'Scalable product platform design based on design structure matrix and axiomatic design', International Journal of Product Development. Vol. 20, No. 2, pp. 91-106.

[2] Leite, M., Baptista, A. J. and Ribeiro, A. M. R. (2016) 'A road map for implementing lean and agile techniques in SMEs product development teams', International Journal of Product Development, Vol. 21, No. 1, pp. 20-40.

[3] Pourjavad, E. and Peng, W. (2017) 'An integrated fuzzy MCDM approach for risk evaluation of new product in a pipe industry', International Journal of Product Development, Vol. 22, No. 3, pp. $165-188$.

[4] Bashir, H. A., Alzebdeh, K., and Abdo, J. (2009) 'An Eigenvalue Based Approach for Assessing the Decomposability of Interdependent Design Tasks', Concurrent Engineering: Research and Applications (CERA Journal), Vol. 19, No. 1. pp. 35-42.

[5] Creese, R. C. and Moore, T. L. (1990) 'Cost modeling for concurrent engineering', Cost Engineering, Vol. 32, No. 6, pp. 23-26.

[6] Lawson, M. and Karandikar, H. M. (1994) 'A survey of concurrent engineering', Concurrent Engineering: Research and Applications, Vol. 1, No. 2, pp. 1-6.

[7] Batallas, D. A. and Yassine, A. A. (2006) 'Information Leaders in product development organizational networks: social network analysis of the design structure matrix', IEEE Transactions on Engineering Management, Vol. 53, No. 4, pp. $570-582$.

[8] Loch, C. H. and Terwiesch, C. (1998) 'Communication and uncertainty in concurrent engineering', Management Science, Vol. 44, No. 8, pp. 1032-1048.

[9] Smith, R. P. and Eppinger, S. D. (1998) 'Deciding between sequential and parallel tasks in engineering design', Concurrent Engineering: Research and Applications, Vol. 6, No. 1, pp. 15-25.

[10] Blanco, E., Grebici, K. and Rieu, D. (2007) 'A unified framework to manage information maturity in design process', International Journal of Product Development, 4, No. 3-4, pp. 255-279.

[11] Moultrie, J., Clarkson, P. and Probert, D. (2006) 'A tool to evaluate design performance in SMEs', International Journal of Productivity and Performance Management, Vol. 55, No. 3, pp. 184-216.

[12] Newman, M. E. J. (2001). Scientific collaborations networks. I. Network construction and fundamental results', Physical Review E, $64 \quad$ (1). Available from https://journals.aps.org/pre/abstract/10.1103/PhysRevE.64.016 131

[13] Varma, C., A., Lee, R. P. and McCullough, J. (2007) 'Information use and new product outcomes: The contingent role of strategy', Journal of Product Innovation Management, Vol. 24, No. 3, pp. 259-273. DOI: 10.1111/j.15405885.2007.00249.x

[14] Yang, Q., Yao, Lu, T., and Zhang, B. (2014) 'An overlappingbased design structure matrix for measuring interaction strength and clustering analysis in product development project', IEEE Transactions on Engineering Management, Vol. 61, No. 1, pp. 159-169.

[15] McCord, K. R., and Eppinger, S. D. (1993) 'Managing the integration problem in concurrent engineering. Cambridge, MA: MIT Sloan School of Management Working Paper No. 3594. Retrieved from http://web.mit.edu/ eppinger/www/pdf/McCord_SloanWP359 4.pdf

[16] Browning, T. R. (1998) 'Integrative mechanisms for multiteam integration: Findings from five case studies, Systems Engineering, Vol. 1, No. 2, pp. 95-112.

[17] Eppinger, S. D. (2001) 'Innovation at the speed of information', Harvard Business Review, Vol. 79, No. 1, pp. 149-158.

[18] Leenders, R. and Dolfsma, W. A. (2016) 'Social Networks for innovation and new product development', The Journal of Product Innovation Management, Vol. 33, No. 2, pp. 123131. 
[19] Kratzer, J., Leenders, R. T. A. J. and Van Engelen, J. M. L. (2010) 'The social network among engineering design teams and their creativity: A case study among teams in two product development programs', International Journal of Project Management, Vol. 28, No. 5, pp. 428-436.

[20] Steward, D. V. (1981) 'Design structure system: A method for managing the design of complex systems', IEEE Transactions on Engineering Management, Vol. 28, No. 3, pp. 71-74.

[21] Browning, T. R. (2006) 'Design structure matrix extensions and innovations: A survey and new opportunities', IEEE Transactions on Engineering Management, Vol. 63, No. 1, pp. 27-52.

[22] Laslo, Z. (2010) 'Project portfolio management: An integrated method for resource planning and scheduling to minimize planning/scheduling- dependent expenses', International Journal of Project Management, Vol. 28, No. 6, pp. 609-618.

[23] Moreno, J. L. (1960) The sociometry reader. Glencoe, Illinois: The Free Press.

[24] Al Zaabi, H., and Bashir, H. (2018) 'Analyzing interdependencies in a project portfolio using social network analysis metrics', The $5^{\text {th }}$ International Conference on Industrial Engineering and Applications (ICIEA). Singapore, April 26-28, 2018. Retrieved from https://ieeexplore.ieee.org/document/ 8387150

[25] Mok, K. Y., Shen, G. Q. and Yang, R. J. (2017) 'Addressing stakeholder complexity and major pitfalls in large cultural building projects', International Journal of Project Management, Vol. 35, pp. 463-478.

[26] Parraguez, P., Eppinger, S. D. and Maier, A. M. (2015) 'Information flow through stages of complex engineering design projects: A dynamic network analysis approach', IEEE Transactions on Engineering Management, Vol. 62, No. 4, pp. 604-617.

[27] Bashir, H., Ojiako, U., and Mota, C. (2020) 'Modeling and Analyzing Factors Affecting Project Delays Using an Integrated Social Network-Fuzzy MICMAC Approach', Engineering Management Journal, Vol. 32, No. 1, pp. 26-36.

[28] Bashir, H. and Ojiako, U. Marshall A., Chipulu M., Yousif, A. A. (2020) 'The Analysis of Information Flow Interdependencies within Projects', Production Planning and Control, Published online: $24^{\text {th }}$ Sep.
[29] Brunelli, M. and Fedrizzi, M. (2009) 'A fuzzy approach to social network analysis', The 2009 International Conference on Advances in Social Network Analysis and Mining (pp. 225230). Available from https://dl.acm.org/citation.cfm?id=1602691

[30] Chu, J., Liu, X. and Wang, Y. (2016) 'Social network analysis based approach to group decision making problem with fuzzy preference relations', Journal of Intelligent \& Fuzzy Systems, Vol. 31, No. 3, pp. 1271-1285.

[31] Yager, R. R. (2010) 'Concept representation in database structures in fuzzy social relational networks', IEEE Transactions on Systems, Man and Cybernetics: Part A, Vol. 40, No. 2, pp. 413-419.

[32] Yager, R. R., Kacprzyk, J. and Beliakov, G. (2011) 'Recent developments in the ordered weighted averaging operators: Theory and practice', Berlin Heidelberg: Springer-Verlag.

[33] Malone, D. W. (1975). An introduction to the application of interpretive structural modeling. Proceedings of the IEEE, Vol. 63, No. 3, pp. 397-404.

[34] Jawad, A. N. A and Bashir, H. (2015) 'Hierarchical structuring of organizational performance using interpretive structural modeling', the 2015 International Conference on Industrial Engineering and Operations Management Dubai (pp. 607-613). United Arab Emirates (UAE), March 3 - 5, 2015. Retrieved from http://ieomsociety.org/ieom_2015/papers/422.pdf

[35] Zadeh, L. A. (1999) 'Some reflections on the anniversary of fuzzy sets and systems', Fuzzy Sets and Systems, Vol. 100, pp., $1-3$.

[36] Pedrycz, W. (1994) 'Why triangular membership functions?', Fuzzy Sets and Systems, 64, 21-30.

[37] Duperrin, J. C. and Godet, M. (1973) 'Méthode de Hiérarchisation des éléments d'un système: essai de prospectivité du système de l'énergie nucléaire dans son contexte sociétal [Hierarchy method elements of a system: test system prospectively of nuclear energy in its societal context]', Commissariat à l'Energie Atomique [Commissioner for Atomic Energy, Report CEA-R-4541], Rapport CEA-R-4541.

[38] R. K. Kazanjian, R. Drazin, and M. A. Glynn, "Creativity and technological learning: The roles of organization architecture and crisis in large-scale projects," Journal of Engineering and Technology Management, vol. 17, pp. 273-298, 2000. 